\title{
Honorable Mention for CNUR816: Health As- sessment at Ryerson University
}

\author{
http://dx.doi.org/10.3991/ijet.v7i2.2081 \\ M. Ahmed, D. Pirner, L. Koechli and M. Glynn \\ Ryerson University, Toronto, Canada

\begin{abstract}
This paper was awarded with an Honorable Mention by the 2011 International E-Learning Awards Academic Division, presented by the International E-Learning Association (IELA)
\end{abstract}

\begin{abstract}
This article provides an overview of the digital learning objects created to address the need for 'hands-on' training in CNUR816: Health Assessment. Online and distance education present unique challenges when it comes to providing skills typically taught in an activity-based learning environment; in this case, Nursing. The following represents one of the ways in which Digital Education Strategies at The Chang School addresses these concerns.
\end{abstract}

Index Terms-Activity-Based Learning, Head-to-Toe Physical Assessment, Learning Objects, Online Delivery

\section{AвOUT US}

Digital Educations Strategies (DES) is a centralized unit within The G. Raymond Chang School of Continuing Education at Ryerson University, which is based in Toronto, Canada. The Chang School is Canada's leading provider of university-based adult education and is a leader in providing applied adult learning that combines academic rigour with practical experience. Annual enrollments at The Chang School number almost 70,000 students, with over 20,000 students in distance courses alone. The Chang School delivers both professional and post-graduate certificates, undergraduate courses, as well as courses that prepare students for accreditation. The Chang School currently offers over 400 courses in distance format, including 14 fully online certificate programs and 22 blended certificate programs that combine online and in-class learning. Flexible delivery options are also provided for online students, such as 13-week fully online, seven-week accelerated online, and one-week accelerated blended.

DES has received numerous prestigious awards from international and national organizations, such as the Sloan Consortium, the Canadian Network for Innovation in Education, and the Canadian Society for Training and Development, each recognizing its work for outstanding quality, innovation, and relevance in the field of digital education. One of the reasons for this success is the collaborative course development model, employed by DES, which ensures high and consistent quality in online offerings. DES works with program areas within The Chang School to design and deliver online and blended courses, focusing on technical and instructional design support for its subject matter experts (SMEs) and instructors. DES collaborates with academic coordinators, and SMEs who are faculty, industry professionals, and community leaders. DES also develops interactive learning objects with its SMEs for use in Ryerson courses. Examples of these learning objects appear on the DES website, http://de.ryerson.ca.

\section{THE CHALLENGE}

Health Assessment (NUR/CNUR816) is one of 13 core nursing courses that are part of the RN Post-Diploma Degree Completion Program at Ryerson University. This course is offered both via The Chang School and the Daphne Cockwell School of Nursing. Upon completion of this course, it is expected that students will be able to perform a systematic physical examination. In order for students to be successful in this process, they must acquire the knowledge and understanding associated with a "Head-to-Toe" physical assessment, i.e. assessing each anatomical system, which includes the eyes, musculoskeletal system, and cardiac system. Students have access to a variety of activities, including learning objects, case studies, and discussion questions, located through the course content to assist them in their learning. This article will focus on discussing the learning objects that were created for this course.

CNUR816 presents a number of design challenges in preparing the learning activities of the course for online delivery. Firstly, students must attain practical skills that are typically taught in person, sometimes on a live subject. Historically, static textbook images have been the primary educational resource for students in this subject area. The second design challenge of CNUR816 is the range of experience the students may bring to the course. Many students coming into this course work within a variety of nursing settings, including the Emergency Department, Intensive Care Units, Medical Units, Mental Health, Public Health, and Administration. As such, they may not regularly carry out complete Head-to-Toe systematic patient assessments. As a result, they may be accustomed to carrying out more focused assessments particular to their area of practice, e.g. neurological, cardiac or abdominal. As a result, they will have a variety of learning needs within the course. A third instructional design challenge of CNUR816 is that many of the skills included in a complete Head-to-Toe assessment are complex, and only mastered with ongoing practice and engagement.

\section{THE SOLUTION}

The Chang School's approach to online course development aligns with adult learning best practices, emphasizing student-centred and activity-based learning. For continuing education and distance students in particular, this approach works well as it encourages them to apply the skills and knowledge they acquire into their profes- 
sional practice. It also takes into account the increasing level of digital literacy demonstrated by students today.

CNUR816, like other online courses at The Chang School, uses a variety of learning objects to motivate and engage students. The benefits of these learning activities are numerous to students. Educational media applications and animations that require learners to 'learn by doing' can help them better retain newly acquired knowledge and skills, and revisit skills and knowledge that they may have not engaged in recently/ frequently, allowing the student to be an active participant in their learning experience. In addition, these objects enable the student to further develop their critical thinking, link to more in-depth reference material, and apply theory to practice independently. These activities allow the student to work at their own pace, demonstrating proper technique, and then providing immediate feedback. Students can practice and master the assessment skills on virtual clients in a safe environment, prior to practicing these skills on each other within a lab setting that is facilitated by an instructor, and eventually assessing a real client in a clinical setting.

These learning objects are shareable and have low technical requirements. They are easily integrated into other courses or programs, including those at other universities and organizations. Bandwidth issues, which may affect students in some international regions, are an important consideration. System requirements for users have been therefore kept low, requiring only an online connection, web browser, and Adobe Flash Player 9.0, which is available at no cost online.

\section{SAMPLE LEARNING OBJECTS}

Below are a few of the many interactive learning objects that are offered specifically to support the learning objectives in CNUR816. These were developed using Adobe Flash ${ }^{\mathrm{TM}}$, XML, SmithMicro Poser $6^{\mathrm{TM}}$, Adobe Illustrator $^{\mathrm{TM}}$, and Adobe Photoshop ${ }^{\mathrm{TM}}$. Instructions are provided with each activity to minimize student misunderstandings and to clarify expectations.

\section{A. Eye Assessment}

The Eye Assessment learning object (see Fig. 1) is a simulation activity that allows students to actively complete a part of the eye examination by going through the necessary assessment steps on a virtual client's eye. Students may select from a number of assessment options in the left menu of the main activity screen. The object is supplemented with relevant theory, instructions, hints, and recommended readings, as well as the opportunity to practice within the activity.

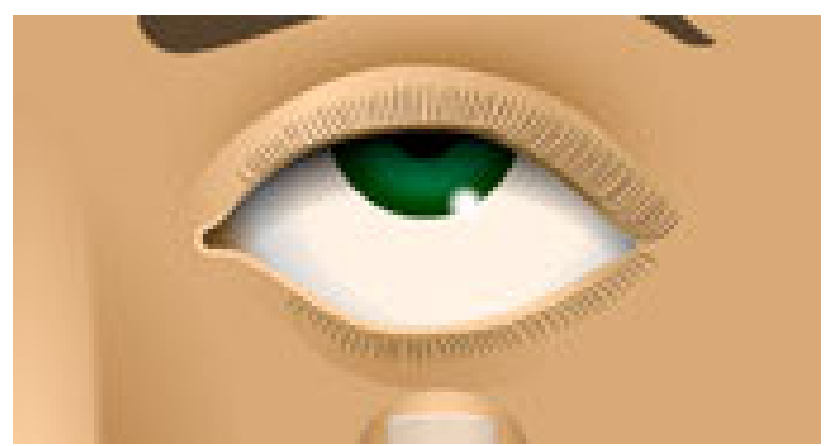

Figure 1. Screenshot of the Eye Assessment learning activity.
The focus is on assessing for normal and non-normal findings. All of the eye evaluation tasks are brought together in one place. While relatively simple tasks, the student can see, in straightforward terms, how to do these assessments and what to expect when they perform the assessments. For example, how will the eye change when a light source is placed in front the eye? In this activity, the student shines a light in the patient's eyes, by turning the light on and off, and moving it from one eye to the other. When the student shines the light in the patient's eyes, he or she can observe for changes in the size of the pupils.

\section{B. Eye Muscles}

The Eye Muscles learning activity (see Fig. 2) provides students with the opportunity to actively move the eye through its possible range of motions by placing the cursor over any of the eye muscles. The specific muscles and the associated cranial nerves involved with each movement, as well as types of action controlled by that muscle, are identified as the student moves the eye in specific particular directions.

\section{Heart Assessment}

The Heart Assessment learning object (see Fig. 3) allows students to actively determine the location of each of the key areas on the heart that need to be assessed during a cardiac assessment and assisting them with familiarizing their ears to both common normal and abnormal sounds that are relevant

The sequence of the assessment is important, and prompts are provided to the student, guiding them throughout the activity. In the first section or "tab" of the activity (Location), the student must identify the five different locations on the heart, and the student is unable to progress to the next activity tab (Sound) until they have succeeded. The student must identify each location in a particular order and they are able to access the contextsensitive hint provided if they cannot recall a location. Upon completion of this task, they see that the configuration of the sound locations assumes a $\mathrm{Z}$ formation. This is a simple mnemonic and it is reinforced visually once the task is complete.

After the first step, the student can either reset the activity or go to the next tab to review and listen and compare the different heart sounds. Under the "Sound" tab, the location of the heart sounds remain visible to allow the student to build on their existing knowledge. There are several sounds that are provided in each location that they can select to listen to.

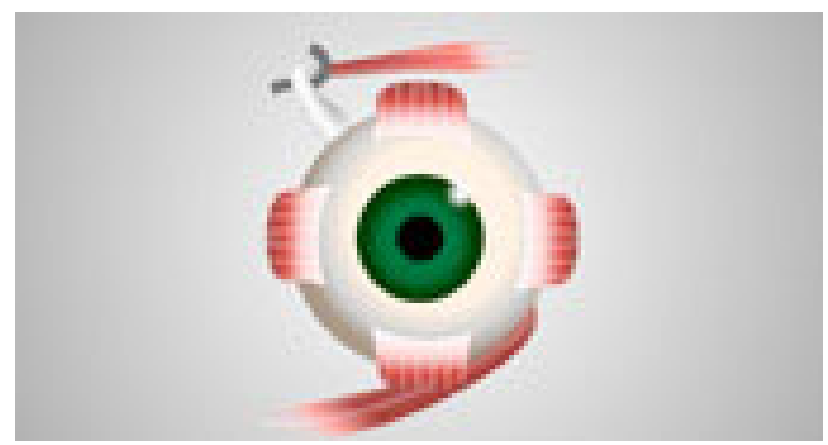

Figure 2. Screenshot of the Eye Muscles learning activity. 


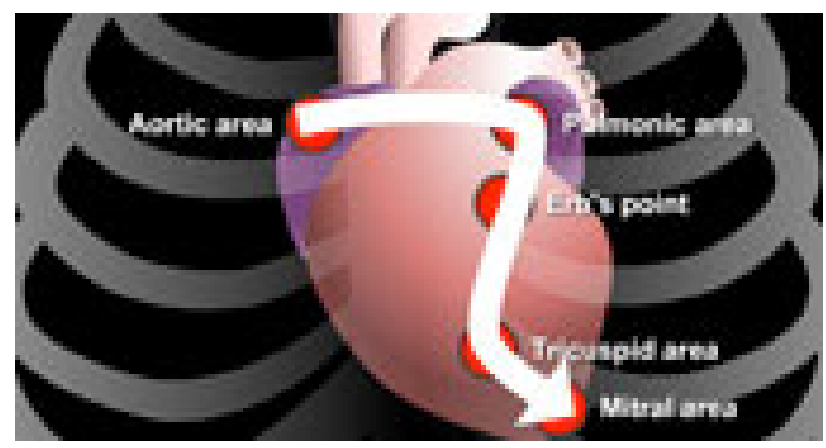

Figure 3. Screenshot of the Heart Beat learning activity.

\section{Range of Motion}

The Range of Motion learning object (see Fig. 4) allows students the opportunity to review and practice the range of motions of each joints in a musculoskeletal assessment. The learning object is designed to show a full range of body motion, employing realistic animation side-by-side with other important information such as angle, distance, and direction of movement. This provides students with a complete representation of the motions that they will ask an assessment client to perform.

For this activity, the user selects one of the body areas from a menu of options, then selects one of the motions and presses the play button that appears in the box. The learning object will demonstrate the action associated with the movement of that particular joint. The learner is also shown the angle of movement, and the type of rotation is identified.

\section{CONCLUSION}

The learning objects in CNUR816 are valuable to the students of this course, and we believe that they may be of value to students/professionals in other Health Care Professions who carry out physical assessments, e.g. Nurse Practitioners, Doctors, Physiotherapists and Occupational Therapists. Each learning object has been designed to be a stand-alone activity that enables students to practice online without the need for an instructor to demonstrate the activity in person. The Chang School invites external users to view these learning objects described in this article online at http://de.ryerson.ca/portals/de/media.html.

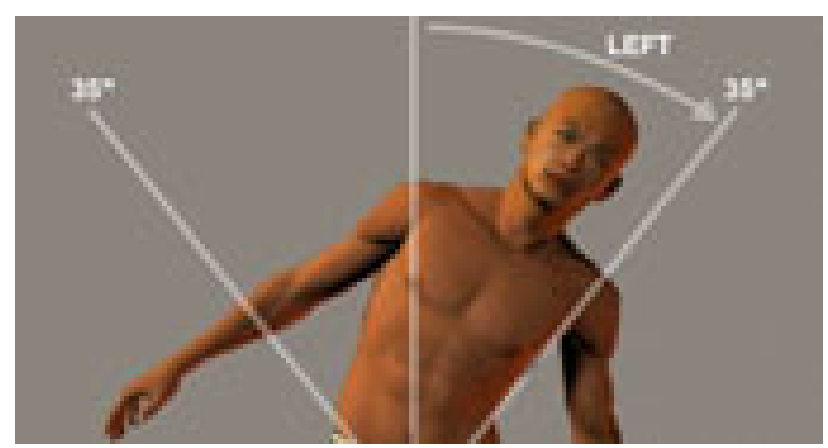

Figure 4. Screenshot of the Range of Motion learning activity.

The Chang School is honoured to be among the institutions recognized in the academic division of the 2011 International E-Learning Awards. The CNUR816 learning objects demonstrate the distinctiveness of this very successful course design. The Chang School continues to emphasize innovation and creativity in the design of all of its online courses as part of its ongoing pursuit of the best possible learning outcomes for all students.

\section{AUTHORS}

M. Ahmed, BSc, is a Project Coordinator within Digital Education Strategies at The G. Raymond School of Continuing Education, Ryerson University, Toronto, Ontario, Canada (mariam.ahmed@ryerson.ca).

D. Pirner, RN, MN, PhD, is an Associate Professor at the Daphne Cockwell School of Nursing, Ryerson University, Toronto, Ontario, Canada (dpirner@ryerson.ca).

L. Koechli, PhD, is the Manager of E-learning Initiatives and Course Development within Digital Education Strategies at The G. Raymond School of Continuing Education, Ryerson University, Toronto, Ontario, Canada (lkoechli@ryerson.ca).

M. Glynn, MPhil, is an Instructional Designer within Digital Education Strategies at The G. Raymond School of Continuing Education, Ryerson University, Toronto, Ontario, Canada (maureen.glynn@ryerson.ca).

Manuscript received 04 April 2012. Published as resubmitted by the authors 27 May 2012. 